\title{
Marketing Mix of 4P'S for Competitive Advantage
}

\author{
Meera Singh ${ }^{1}$ \\ ${ }^{1}$ (Computer Department (H.S.S), G.H. Raisoni Institute of Engineering \& Technology/Pune University, India)
}

\begin{abstract}
The Marketing Mix comprises of four decisions which should be considered before launching a product. Firms should plan targeted approach on these four different components and they are Product, Price, and Place \& Promotion. All the four variables help the firm in formulating strategic decisions necessary for competitive advantage. The main objective of this article is to describe the importance of relationship of various components of marketing mix for attaining competitive advantage in market. Marketing Mix comprises of Product marketing mix and Service marketing mix. Generally the Product marketing mix consists of product, price, place and promotion and it is generally used for marketing mix of tangible goods. However Service marketing mix is related to three different variables for example people, process and physical evidence. The term marketing mix became popular when Neil H. Borden published his article on "The concept of Marketing Mix" in 1964. The marketing mix is characterised by four equally important variables. The first step is Product plan for articulating a marketing plan. There are three parts of product plan, i.e. core product, augmented product and the tertiary product. Not only product related decisions but also price related decisions like whether the uniform price will be charged or different prices will be charged for the same product in different markets. The third variable is 'Place' and it is related to the decisions like where the product will be sold. 'Promotion' decisions are related to increase the sales. The marketing mix involves the decisions related to which the products will be made available at a particular price, may be different price will be charged for the same product as per different market, the marketing manager has to take into account the impact of different factors which are categorised under the $4 P$ 's to decide marketing mix for a product.
\end{abstract}

Keywords: Marketing Mix, Product, Price, Positioning, Promotion, Competitive Advantage

\section{INTRODUCTION}

Marketing mix is the combination of different marketing decision variables being used by the firm to market its goods and services. After identifying the market and gathering the basic information about it, the next step is the direction of market programming, is to decide upon the instruments and the strategy to meet the needs of the customers and the challenge of the competitors. It offers an optimum combination of all marketing ingredients so that companies can realise goals for example profit, sales volume, market share, return on investment etc.The marketing mix is grouped under four elements i.e., Product, Price, Place, Promotion [1]. A profitable formula of marketing operations is that mostly marketing mix changes as per marketing conditions and also with changing environmental factors.

The marketing mix is a set of controllable variables that the company can use to influence the buyers responses. Thus marketing manager decides the level of marketing expenditure in order to achieve marketing objectives of the firm and after finalising the market budget it is decided that how to divide total marketing budget among various tools in the marketing mix.

Marketing decisions are categorised in the following table no.1 below:

Table No. 1 Elements of 4 P's

\begin{tabular}{|l|l|l|l|}
\hline Product & Price & Promotion & Place \\
\hline Design & Retail & Strategies & Special offers \\
Technology & Wholesale & Skimming & Endorsements \\
Usefulness & Internet & Penetration & Advertising \\
Value & Direct sales & Psychological & User trials \\
Convenience & Peer to peer & Cost-plus & Direct mailing \\
Quality & Multi channel & Loss leader & Leaflets/posters \\
Packaging & & & Free gifts \\
Branding & & & Competitions \\
Warranties & & & Joint ventures \\
\hline
\end{tabular}

The term marketing mix is coined by Neil H. Borden. It is the combination of the fair inputs of all the important elements or ingredients that make up the marketing programmes as mentioned in the Fig.1. It 
constitutes the core of company's style of marketing. All these elements are very significant and depend upon each other; the four elements in the marketing mix are inter related.

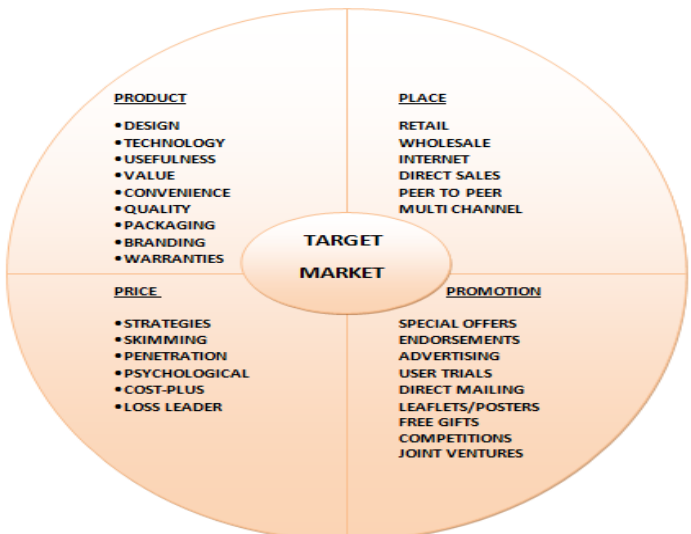

Fig. 1 Marketing Mix Cycle

\section{CURRENT TREND}

Always there are different factors that influence the development of strong customer relationships in market [2]. Organizations are concentrating on the strong exchange relationships; and an understanding of relationship value of a customer as there is a framework which suggests that interrelationship between the variables of marketing mix at different levels. Each successive level of strategies results in ties that bind the customer little closer to the firm.

\subsection{Product}

Product refers to a physical product or service for a consumer is ready to pay. It includes tangible goods like furniture; garments, grocery items etc and intangible products like services are purchased by consumers. The product is the key element of any marketing mix.

\subsubsection{Product Life Cycle}

It denotes the different stages through which the sale of any product changes in a time period. There are four stages- introduction stage, growth stage, and maturity and decline stage. A product is introduced in the market then it gains more and more customers as it grows [3]. Gradually the market stabilises and the product becomes mature there after a period of time it declines because of the development and introduction of superior competitors and is eventually withdrawn as shown in the figure.

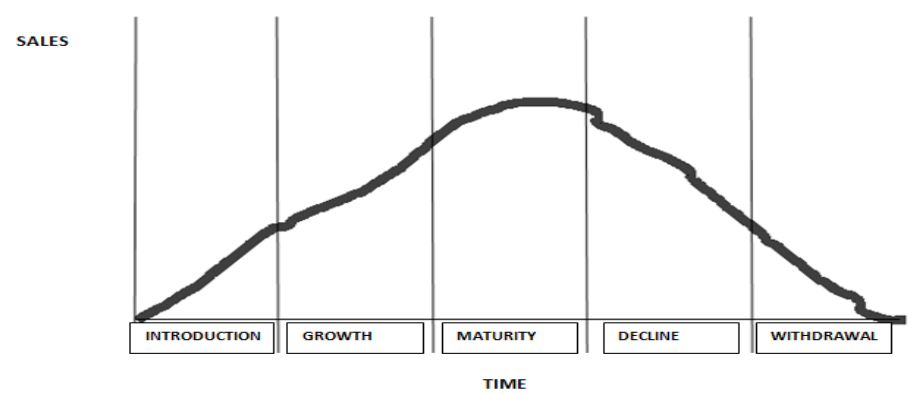

Fig. 2 Product Life Cycle

\subsubsection{Customer Life Cycle}

The Customer Life Cycle (CLC) focuses on the building life time customers by creation and delivery of value throughout the life of a customer. It incarnates the concept of marketing because this concept is marketing oriented rather than product oriented. One amongst the crucial problem here is that generally every organisation offers different types of product; hence it is inconceivable to maintain a uniform Customer Life Cycle for every organisation.

For an illustration CANARA BANK has a number of products that it aims at its customers to maintain lifetime relationship with it. An individual can start saving money at young age.12-15 year old are directed with the live cash Account similarly 16-17 year old aimed with the Right Track Account. When an individual begins to go in college or university then student loans are available and when he begins to work there are many types of current and saving account. Apart from it he can also obtain home loan to buy a flat, car loan to buy a car. It 
would be beneficial to take out a pension plan. As he progresses in his life then his family extends then he ventures upon number of saving plans and schemes. Ultimately CANARA BANK offers him pension plans due to this kind of strategies an organisation such as CANARA BANK can form and hold customers and then widen additional products and services throughout a customer's life.

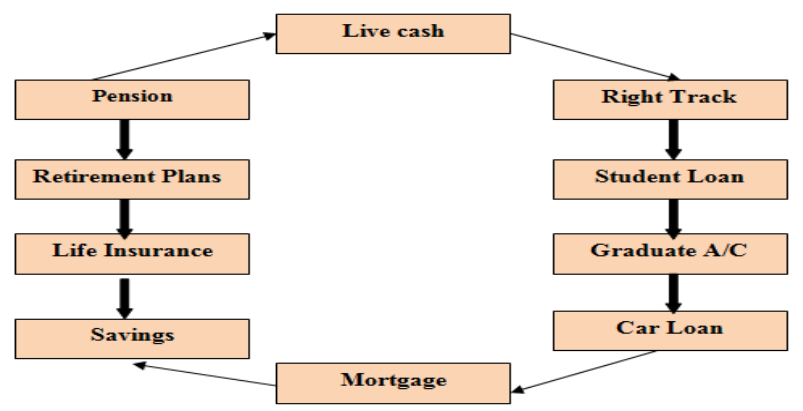

Fig. 3 Customer Life Cycle

\subsection{Price}

Price is the amount the consumer must exchange to receive the offering [4]. As the price of a product depends on different elements and hence it is changes constantly thus the pricing should be dynamic so that it can bear the changes over duration. The important factor in pricing is the deciding the cost of the product, strategy for marketing \& its expenses related to distribution, advertisement expenses or any kind of price variation in the market. Nonetheless if there is change in all the variables then generally the pricing of the product may vary accordingly.

\subsection{Promotion}

Promotion is one of the most powerful elements in the marketing mix [5]. Sales promotion activities are publicity, public relations, exhibition and demonstrations etc. It is marketing manager who decides the level of marketing expenditure on promotion. Promotional activities are mainly intended to supplement personal selling, advertising and publicity. Promotion helps the trader and sales force to represent the product $t$ the consumers in an effective manner and induce them to buy. Promotion consists of different blends of its components which are used to achieve the company's marketing goals.

Advertising is a powerful element of promotion mix. The main aim of the advertising is to create and develop the image of a product in the market. It is one of the important tools of competition which maintains the dynamism of industry. Promotion mix decides the positioning of the product in the target market. It should be considered as expenditure and hence added to the cost of a product.

\subsection{Place}

It includes distribution channels, warehousing facilities, mode of transportation and inventory control management thus it is a mechanism through which goods and services are moved from the service provider and manufacturer to consumer. If the product is a business product then a business team is required to interact with different clients and ensure the availability of the product for them. Distribution has a huge effect on the profitability therefore a firm should have excellent supply chain and logistics management plan for distribution.

All the four variables of marketing mix are interconnected. By increasing the price of the product, the demand of the product will be lessened and lesser distribution points will be required. On the other hand, the product USP can be such that maximum concentration is on creating brand cognisance hence better pricing for a product. Finally, the overall marketing mix can result in dynamic modelling based on customer feedback for improving a product and the same can be launched as the upgraded product.

\section{Marketing Mix of 4 P's for Competitive Advantage: A Challenge}

Marketing Mix is the combination of four elements i.e. Product, Price, Promotion and Place and every company has the option to design an optimum admix in order to create a trusted marketing strategy. The marketing manager has to consider the behavioural forces and then decide marketing elements in his mix considering the available resources. The manager must examine the resources of the company to decide a mix of procedures that fit the resources. The top level management has to support their effort in supporting new ways of business through the organization. 


\subsection{Theoretical Approach}

Due to no specification on how much percentage of attention to product planning mixed with pricing or how much of pricing. Or how much of physical distribution and how much of promotional efforts would bring about an optimum result hence it cannot substitute an individual's strategy. It is theoretical in nature.

\subsection{Lack of Uniformity}

There is no uniform opinion about the composition of the variables of marketing mix. It has led to confusion and difficulty to understand the components of four elements.

\subsection{Changing Environment}

Marketing mix is dynamic and flexible concept. Thus it changes with the change in needs and preferences of the customers and market forces like competition, government policies and marketing situation.

\subsection{To Identify Target Customers}

The marketing manager has to identify the target customers by discovering their needs as well as expectations for deciding appropriate marketing mix. Proper market research, foresighted approaches are very important factors to locate target markets.

\section{Strategies for marketing mix of 4p's for competitive advantage}

The Marketing mix by 4P's is a conjuration and it can only be implemented by marketing managers. Marketing mix is a greatest strategy for attaining competitive advantage for any firm. The customer is king thus it is mandatory to employ excellent marketing mix by marketing manager is essential as these key elements will satisfy the customer needs and demands. It is highly necessary to plan and implement appropriate Marketing Mix of 4P'S for competitive advantage. Marketing management is about placing the right product, at the right price, at the right place, at the right time. Following are the strategies for marketing mix by $4 \mathrm{p}$ 's for competitive advantage:

\subsection{Product Mix}

A product, service is the starting point of all marketing activities. A product is a combination of different attributes. It comprises of physical factors such as colour, design, features, performance and non physical factors like value, quality etc. Product planning involves a variety of decision to be taken firmly to bring the product in the market. Decisions concerning to product are related to the following -

4.1.1 Design is very important in a today's world as it is all about gaining attention, focusing it on the product and influencing the purchase decision of the customers. The design is directly linked to show success and makes the difference because it leads to goal achievement.

4.1.2 Technology should be used to develop user friendly new products with product differentiation.

4.1.3 Usefulness of product can increase market share of the product as it is very essential component to have competitive advantage in the market a product should be developed keeping extra uses in comparison to same type of product available in the market. Product differentiation is established in the market by increasing the usefulness of a product.

4.1.4 Value is something which is a look around of companies while developing a product so that if customers are paying then they should not feel that they have been charged more than the manufacturing cost of the product. Hence high performance product which meets or exceeds a customer demand related to a product's performance should be developed.

4.1.5 Convenience is a parameter related to usage of the product and the product should bring ease in life of customer.

4.1.6 Quality gains customers as an individual always looks for good quality product or service.

4.1.7 Packaging is used for raising the product's value. For an illustration, McDonald's had changed its package design across 118 countries. Packaging increases the perceptual experiences about the quality of the product.

4.1.8 Branding usually assures high or at least consistent quality and hence encourages repeat purchasing.

4.1.9 Warranties give an assurance to the customer about after sales service which assures the customer about the durability of the product and maintains satisfied customers in the market.

\subsection{Price Mix}

The price is the amount a customer pays for a product. It is ascertained by various factors including cost of material, product differentiation, competition, market share and the customer's perceived value of a product [6]. The decisions related to the price are as follows- 
4.2.1 Strategies pricing involves important decisions for a firm as there can be an option to fix the price of the product on competitive basis, in this a marketer selects a competitive pricing strategy as he actually seeks to compete on the basis of superior distribution, appealing advertisements and several other factors.

4.2.2 Skimming means pricing the product relatively high in comparison to the similar commodities and then gradually reducing the price. The strategy of skimming allows the firm to recover its cost rapidly by maximizing its sales revenue thus skimming strategy has been used effectively on gadgets like LCD's, calculators, laptops and DVD players.

4.2.3 Penetration pricing means fixing the price of the product comparatively low to similar goods assuming that it will capture wide market and this will allow the company to raise the price of its product.

4.2.4 Psychological pricing is used all over the world therefore marketers believe certain prices are more appealing than others to buyers this kind of image pricing are often envisioned. The psychological pricing is done by the retailers by using price tag like `39.95, `19.98 or `9.99.

4.2.5 Cost-plus is a concept in which some companies try to maximize their profits by pricing their offerings very high [7]. Every firm has different pricing objectives. It is the process of cost-based pricing where by adding all costs associated with offering a commodity in the market by including the expenses related to the production, transportation, distribution as well as marketing also an amount is added to cover profit.

4.2.6 Loss leader means use of low prices to attract new business. A marketer who selects a competitive pricing strategy is attempting to use non price competition.

\subsection{Place}

Place is generally referred to as the distribution channel [8]. Place can be any physical store as well as virtual stores. The process involved in transferring products from the producer to the consumer is known as physical distribution. The decisions related to the place are following -

4.3.1 Retail. Retailers will have a much stronger relationship with the customer because he keeps several other products of different brands this will lead to exposure of the consumer to many products. Often products and services are promoted and merchandised by the retailers.

4.3.2 Wholesale. Wholesalers often cut down the price of a product in comparison to retail traders. Hence the customers are generally satisfied to buy the product from them. Wholesalers print their own brochures to promote sales of manufacturers. But they should be given some commission in the total sales revenue.

4.3.3 Internet. Generally customers buy products online by using web sites like Flipkart, eBay, Amazon, Jabong etc. The main benefit of the Internet is that niche products reach a wide population with low entry barriers as set up costs are comparatively less hence there is a epitome shift in commerce and consumption via the Internet this led to a huge growth in e commerce.

4.3.4 Direct sales in any marketing are undertaken without a distributor or intermediary. In terms of promotion it means that the marketing company has direct communication with the customer. For example Aquaguard distributes through retailers however a customer can register directly with them for information which is often delivered by e-mail or mail.

4.3.5 Peer to peer is a type of word of mouth as if a product is admired by an individual then he conveys the message to his peer group and in market it is really effective.

4.3.6 Multi channel is very useful to have market share for different products and services and hence their manufacturers or providers use different distribution channels. For example, a diamond ring can be bought directly from the Gold smith, either on the telephone, or the Internet.

\subsection{Promotion Mix}

Promotion activities are meant to communicate \& persuade the target market to buy the company's products. The firm chooses the product to meet the identified need of the target segment. The right distribution channel is used to make the product available and the firm undertakes attention-getting promotion. The decisions concerning promotion are related to the following -

4.4.1 Special offers are like buy one and get one free of cost or may be coupons, discounts, free accessories (such as free blades with a new razor), introductory offers (such as buy LCD and get free set top box), and so on.

4.4.2 Endorsements are important for promotion because consumers follow their role models, celebrities and thus endorsement brings change in the mindset of the consumers.

4.4.3 Advertising is an important way of communication hence it is used to create awareness, and transmit information in order to gain customers from the target market. There are many advertising mode and media for example magazines, journals, movies television, Ad labs, outdoor advertisements (such as posters) and newspapers.

4.4.4 User trials convince customers about the features of the product. It is important as any customer would like to have a trial before buying it. 
4.4.5 Direct mailing is very highly focussed upon targeting consumers based upon a database. As with all types of marketing, the potential consumer is targeted based upon a series of attributes. Different agencies work to design a highly focussed communication in the form of mails. The mail is marked to the potential customers and responses are cautiously monitored.

4.4.6 Leaflets/posters are the mode of direct communication through with the information of the product is conveyed to the customer and it is very effective.

4.4.7 Free gifts should be offered with the product because consumers look for additional benefits apart from a good product.

4.4.8 Competitions create innovation and hence this spirit keeps alive the invention of new and creativity in existing products in an organisation.

4.4.9 Joint ventures with suppliers and distributors bring more customers because the suppliers and distributors become stake holders and they show interest in promoting the product.

\section{CONCLUSION}

This report is an overview of the past, present and future of the Marketing Mix of 4P'S for competitive advantage. This report considers a wide view of Marketing Mix of 4P's, as the biggest challenges before the Marketing professionals in today's world is to design an optimum marketing mix which takes care of both customer's satisfaction and organisational goals. All the elements of marketing mix need careful alteration and minute study with complete concentration. Promotional tools depend upon the type of product, the price which will be charged for the product and the procedure through which it would reach to the customer furthermore while deciding the price of product; the important things to consider are manufacturing cost of the product, promotion cost and amount incurred on distribution channels.

Marketing manager should be an expert in deciding marketing mix strategy by 4 P's as marketing mix has a very important role for attaining competitive advantage for the organization. Marketing manager should meet the demand from different markets and also match the competition in the market by delivering satisfaction to the customer. This is only possible by an accurate blend of all the elements 4P's of marketing mix as it helps in achieving organisational goals of profit maximization by high sales volume and attaining higher market share.

\section{References}

[1] Abrams, Rhonda (2000), Successful Business Plan: Secrets and Strategies, (Palo Alto; California: Running 'R' Media), xxix, Sec. II p 47-288.

[2] Arthur Anderson (1998), Best Practices: Building You Business with Customer-Focused Solutions. New York: Simon \& Schuster, pp. $125-27$.

[3] Borden, Neil H (1942). The Economic Effects of Advertising. Homewood, 111: Richard D. Irwin.

[4] Borden, Neil H \& M. V. Marshall (1959). Advertising Management: Text and Cases. Homewood, III, Richard D. Irwin.

[5] Culliton, James W (1948). The Management of Marketing Costs. Boston: Division of Research, Graduate School of Business Administration, Harvard University.

[6] Davenport, Thomas H. and Jeanne G. Harris (2007), Competing on Analytics: The New Science of Winning. Boston: Harvard Business School Press.

[7] Kotler, Philip (1971), Marketing Decision Making: A Model-Building Approach. New York: Holt, Rinehart and Winston.

[8] Rasmussen, Andrea, Carolyn Ude, and Edward Landry (2007), HD Marketing 2010: Sharpening the Conversation. New York: Booz Allen Hamilton. 